\title{
Selection of Surgical Technique and Treatment Outcome of Revision Septoplasty
}

\author{
Min Joo Kim and Yong Ju Jang \\ Department of Otolaryngology, Asan Medical Center, University of Ulsan College of Medicine, Seoul, Korea
}

비중격성형술 재수술의 술식 선택과 치료 결과

김 민 주·장 용 주

울산대학교 의과대학 서울아산병원 이비인후과학교실

\author{
Received March 27, 2017 \\ Revised June 20,2017 \\ Accepted July 1, 2017 \\ Address for correspondence \\ Yong Ju Jang, MD, PhD \\ Department of Otolaryngology, \\ Asan Medical Center, \\ University of Ulsan \\ College of Medicine, \\ 88 Olympic-ro 43-gil, Songpa-gu, \\ Seoul 05505, Korea \\ Tel $+82-2-3010-3712$ \\ Fax $+82-2-489-2773$ \\ E-mail jangyj@amc.seoul.kr
}

\begin{abstract}
Background and Objectives This study was designed to review our experience with patients undergoing revision septoplasty and to evaluate the causes of persistent nasal obstruction and treatment outcomes of revision septoplasty.

Subjects and Method The medical records of 58 patients (53 men) who underwent revision septoplasty by the author of this study between 2006 and 2012 at our institute were retrospectively reviewed. Data on demographics, symptoms, anatomic site of deviation, surgical techniques performed, and postoperative complications were collected. Patient satisfaction scores were graded with a grading scale from 1 (excellent) to 4 (poor).

Results All of the patients visited our hospital for persistent nasal obstruction after prior septoplasty. Forty-seven patients (81\%) showed caudal septal deviation and 11 (19\%) showed some other forms of septal deviation. Twenty-one cases $(36.2 \%)$ were treated with the batten graft with cutting and suture technique, $20(34.5 \%)$ with a batten graft alone, $10(17.3 \%)$ with resection of remnant deviated septal bone and cartilage, $4(6.8 \%)$ with the cutting and suture technique, $2(3.5 \%)$ with a relocation suture, and $1(1.7 \%)$ with a spreader graft. The median patient satisfaction score for 31 patients who answered the telephone interview was $2.06 \pm 0.93$.

Conclusion A considerable number of patients who undergo revision septoplasty have remnant or recurrent caudal septal deviation that was not properly corrected in previous surgery. We recommend the batten grafting and the cutting and suture technique for the correction of caudal septal deviation in revision septoplasty.
\end{abstract}

Korean J Otorhinolaryngol-Head Neck Surg 2017;60(12):640-5

Key Words Caudal $\cdot$ Deviation $\cdot$ Post-operative $\cdot$ Revision $\cdot$ Septoplasty.

\section{Introduction}

There are many causes of nasal obstruction, including inferior turbinate hypertrophy, nasal valve collapse, deviated nose, nasal polyp, and, the most important of all, septal deviation. Although anatomic deviation of the septum is a common

This is an Open Access article distributed under the terms of the Creative Commons Attribution Non-Commercial License (http://creativecommons.org/licenses/by-nc/4.0) which permits unrestricted non-commercial use, distribution, and reproduction in any medium, provided the original work is properly cited. finding in the general population, not all patients with septal deviation complain about nasal obstruction. ${ }^{1)}$ Therefore, those patients who have persistent symptoms after medical treatment may consider septoplasty to correct the deviated nasal septum.

Septoplasty is one of the most frequently performed rhinologic procedures. ${ }^{2)}$ However, deviated septum management is difficult due to the difficulty in overcoming intrinsic cartilage memory. If the deviation is not corrected properly at the 
primary surgery, septal deviation and nasal obstruction can persist due to remnant deviation. Overcorrection of the septum, intrinsic weakening of nasal support, inferior turbinate hypertrophy, nasal valve obstruction, and allergic rhinitis can be the causes of failed correction of nasal obstruction after septoplasty. ${ }^{3)}$ To obtain a satisfactory outcome after primary surgery, correct diagnosis of the problems and an adequate treatment plan are required.

Various approaches and techniques for septoplasty have been developed. Although the standard endonasal septoplasty technique is usually performed, endoscopic and external approaches can also be used according to the location of the deviation or combined nasal problems. ${ }^{4)}$ In spite of technical advancements in the septoplasty procedure, the needs for revision septoplasty still exist in many patients.

Despite its clinical importance, few reports have described the underlying causes and selection of surgical techniques in revision septoplasty. In this study, we aimed to review our experience with patients undergoing revision septoplasty and to try to evaluate the causes of persistent nasal obstruction and treatment outcomes based on our treatment algorithm.

\section{Subjects and Method}

\section{Study design and patient selection}

This study was approved by the Institutional Review Board of Asan Medical Center, Seoul, South Korea (2010-0669). The medical records of 58 patients (53 men) who underwent revision septoplasty by an author of this study (Y.J.J.) between 2006 and 2012 at the Department of Otolaryngology in Asan Medical Center were retrospectively reviewed. The mean patient age was 37 years (range, 20-65 years) and the mean follow-up period was 5.3 months. The data analyzed included patient age, gender, surgeon who performed the previous septoplasty, anatomical location of deviation, surgical techniques, postoperative complications, subjective satisfaction, and recurrence. Types of deviation after primary surgery was diagnosed based on nasal endoscopic findings and the Cottle test at an outpatient clinic. Operative notes were reviewed for the surgical techniques. Patient satisfaction was determined by telephone interview. Outcomes were classified as excellent, good, no change, or poor. Satisfaction scores were graded by using a grading scale from 1 (excellent) to 4 (poor). Postoperative records were reviewed to assess complications and recurrence of deviation.

\section{Surgical techniques}

All surgery was performed via an endonasal approach except in one case in which an external approach was used. After making a hemitransfixion incision $2-3 \mathrm{~mm}$ behind the caudal region of the concave nasal cavity, the submucoperichondrial flap of the septum was elevated with a Freer elevator. The residual curved portion of the septal cartilage and bone was harvested, leaving an L-strut of dorsal and caudal cartilaginous septum at least $1.5 \mathrm{~cm}$ long. If caudal septal deviation existed, a contralateral flap was elevated from the caudal aspect of the cartilage without making an incision on the opposite side. For the caudal septal deviation without dislocation, a septal batten graft was applied on the concave side (Fig. 1A). In some severe cases, the caudal strut was cut with scissors at the most convex region in the caudocephalic direction. The excess portions of the upper and lower caudal strut were then overlapped, and the overlapping cartilages were sutured together with 3-4 stitches. A batten graft was also applied with the cutting and suture technique for further support (Fig. 1B). In addition, when caudal septum and anterior nasal spine were dislocated, a relocation suture was done after separating caudal septum from anterior nasal spine (Fig. $1 C)$. When there was significant residual deviation of the dorsal border of the septum, a spreader graft was used to splint the dorsal septum into a straight configuration. For non-cau-
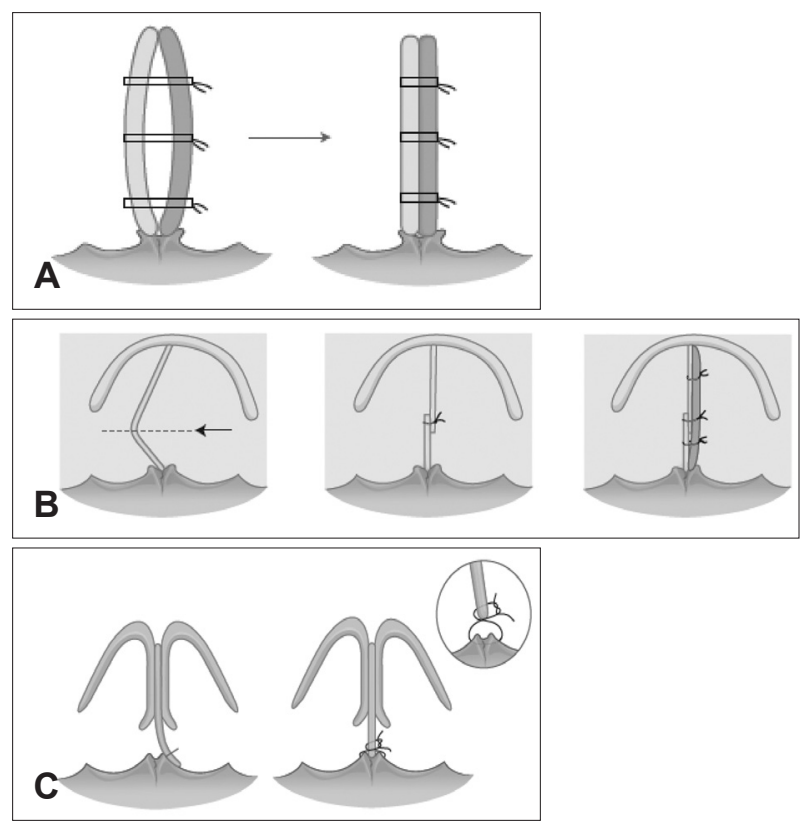

Fig. 1. Illustration of the caudal septal batten graft technique (A). Cutting and suture technique of the caudal L-strut with batten graft (B). Relocation suture of the dislocated caudal septum (C). Adapted from Jang. Rhinoseptoplasty 2013. p.77-81, with permission of Koonja. ${ }^{22)}$ 


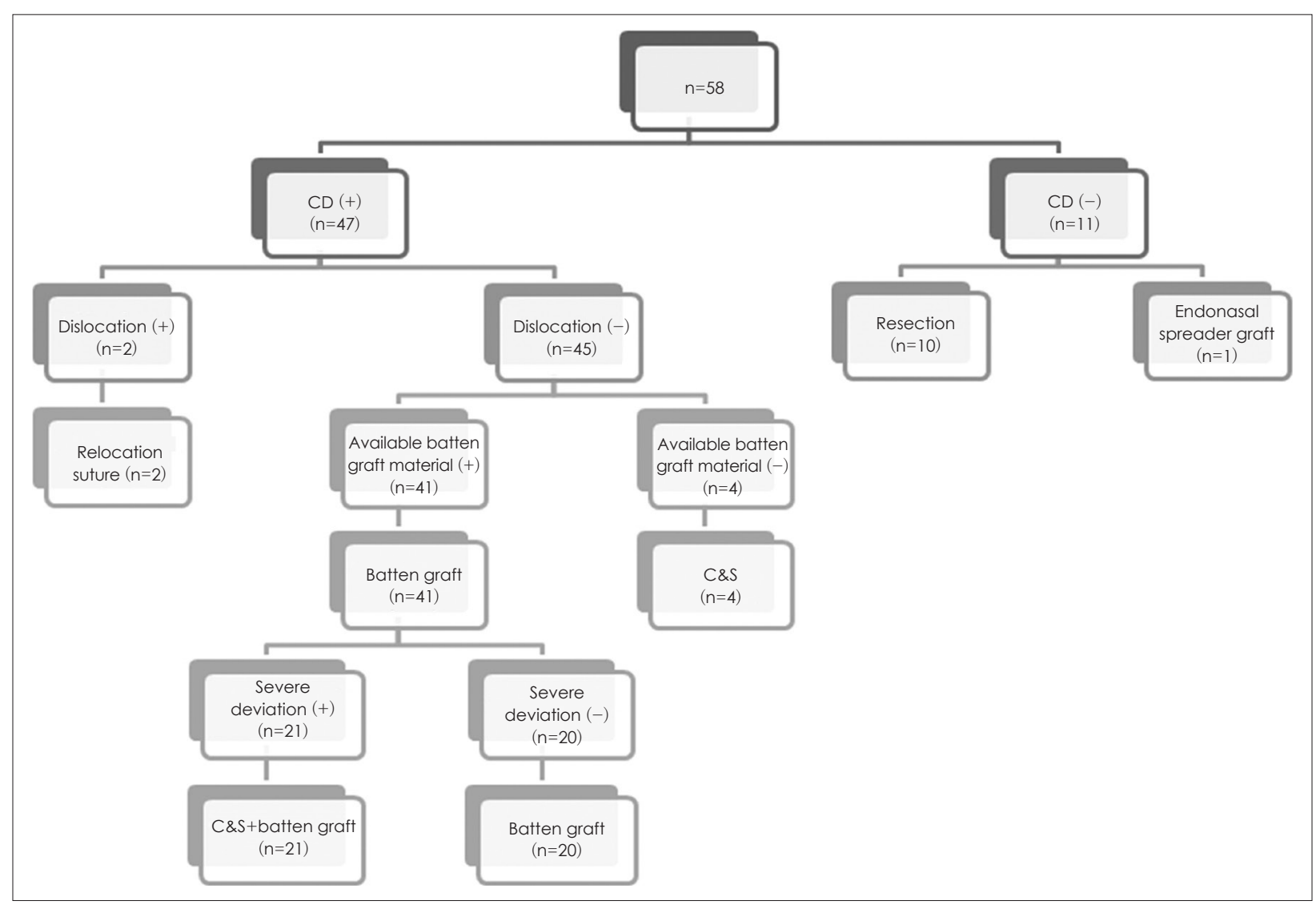

Fig. 2. Our treatment algorithm employed for the management of the remnant septal deviation. CD: caudal deviation, C\&S: cutting and suture technique.

Table 1. Patient characteristics

\begin{tabular}{lc}
\hline \multicolumn{1}{c}{ Patient characteristics } & No. of patients (\%) \\
\hline Sex & $53(91.4)$ \\
Male & $5(8.6)$ \\
Female & \\
Previous surgeon & $15(26)$ \\
Author's own revision & $43(74)$ \\
Others & \\
Number of previous septoplasties & $50(86.2)$ \\
1 & $6(10.3)$ \\
2 & $2(3.5)$ \\
3 & $47(81)$ \\
Anatomic site of deviation & $11(19)$ \\
Caudal septum & \\
Others &
\end{tabular}

dal or -dorsal deviation forms, only the remnant curved portions were resected. The algorithm of the revision septoplasty used in our study is shown in Fig. 2.

\section{Statistical analysis}

Mann-Whitney test was used to analyze the effect of inferi- or turbinate procedures at the revision surgery on subjective satisfaction score. Statistical significance was considered when the $p$ value was $<0.05$. Statistical analysis was performed using SPSS Statistics 19.0 (IBM Corp., Armonk, NY, USA).

\section{Results}

Baseline characteristics of the study patients are summarized in Table 1. Of the 58 patients, 15 (26\%) were revision cases of an author of this study (Y.J.J.) and 43 (74\%) were cases of other surgeons. Fifty cases (86.2\%) were first revision cases, six (10.3\%) were second revision, and two (3.5\%) were third revision. Based on preoperative endoscopic examinations, 47 patients (81\%) had a caudal septal deviation. The other sites of the deviation were mid-part cartilaginous septum in $8(14 \%)$, bony septum in 2 (3.4\%) and dorsal septum in 1 (1.6\%). Whereas 57 patients underwent revision septoplasty via the endonasal approach, one patient who had a combined large septal perforation underwent revision septoplasty and perforation repair via the external approach.

A variety of techniques were used to correct the deviations 
Table 2. Surgical techniques used for revision septoplasty

\begin{tabular}{lc}
\hline \multicolumn{1}{c}{ Techniques } & No. of patients (\%) \\
\hline Approach & $57 / 58(98)$ \\
Endonasal & $1 / 58(2)$ \\
External & $21 / 58(36.2)$ \\
Batten graft+cutting \& suture & $20 / 58(34.5)$ \\
Batten graft & $10 / 58(17.3)$ \\
Resection of remnant deviated & \\
septal bone, cartilage & $4 / 58(6.8)$ \\
Cutting \& suture & $2 / 58(3.5)$ \\
Relocation suture & $1 / 58(1.7)$ \\
Resection+spreader graft & \\
Materials of batten graft* & $26 / 41(63.4)$ \\
Septal cartilage & $10 / 41(24.4)$ \\
Septal bone & $5 / 41(12.2)$ \\
Conchal cartilage & \\
\hline
\end{tabular}

*analysis was done in 41 patients who underwent batten grafting among a total of 58 patients who had revision septoplasty

(Table 2). The batten graft with the cutting and suture technique was used in 21 cases (36.2\%), and 20 patients (34.5\%) received the batten graft alone. A simple resection of the deviated septal bone and cartilage was done in 10 patients $(17.3 \%)$, the cutting and suture technique alone was used in 4 cases (6.8\%), a relocation suture of caudal septum was used in 2 cases $(3.5 \%)$, and resection of deviated septal bone and cartilage with a spreader graft was used in 1 patient (1.7\%). Among the 58 patients, 41 had a batten graft as one of their surgical procedures. Septal cartilage (63.4\%) was the most commonly used graft material, followed by septal bone (24.4\%) and conchal cartilage (12.2\%).

Subjective satisfaction was investigated for the 31 patients who agreed to a telephone interview. Patient self-assessment was rated as excellent by 10 patients (32.3\%), good by $11(35.5 \%)$, no change by $8(25.8 \%)$, and poor by $2(6.4 \%)$. The mean patient satisfaction score was $2.06 \pm 0.93$. Inferior turbinate procedures such as radiofrequency turbinate volume reduction, inferior turbinate lateralization, and turbinectomy had no statistically significant relationship with postoperative subjective satisfaction score $(p>0.05)$.

Complications after surgery included persistent nasal obstruction in 3 patients, septal hematoma in 3 patients, wound infection in 2 patients, synechia in 2 patients, septal perforation in 1 patient, and mucosal defect in 1 patient (Table 3 ). Among the 58 patients, additional surgical procedures were performed during the follow-up period in 3 patients. One patient who had persistent nasal obstruction underwent radiofrequency turbinate volume reduction and another patient
Table 3. Complications after revision septoplasty

\begin{tabular}{lc}
\hline \multicolumn{1}{c}{ Complications } & No. of patients (\%) \\
\hline Persistent nasal obstruction & $3 / 58(5.2)$ \\
Septal hematoma & $3 / 58(5.2)$ \\
Wound infection & $2 / 58(3.4)$ \\
Synechia & $2 / 58(3.4)$ \\
Septal perforation & $1 / 58(1.7)$ \\
Mucosal defect & $1 / 58(1.7)$ \\
\hline Total & $12 / 58(20.6)$
\end{tabular}

who had a mucosal defect after revision septoplasty underwent a skin graft with postauricular skin under local anesthesia. One patient underwent open rhinoplasty for personal aesthetic requirements. No patient required revision septoplasty due to persistent or recurrent septal deviation during the follow-up period.

\section{Discussion}

When performing revision septoplasty, the surgeon requires various special technical skills to achieve a satisfactory outcome. Elevating the submucoperichondrial flap in revision cases is difficult because of adhesion between the flap and the remnant septum that was manipulated in the previous surgery. Weakened septal cartilage framework incurred during the primary septoplasty also limits the choice of available surgical options. These difficulties may increase the complexity of the surgical maneuver and complication rates, and further jeopardize structural stability of the nose.

This study examined causes of persistent nasal obstruction, their surgical management, and the outcomes of a revision septoplasty based on our treatment algorithm. We found that caudal septal deviation is one of the most important causes of revision septoplasty. Thus, the use of proper surgical techniques for the correction of caudal septal deviation is critical for achieving successful results from revision surgery. Surgical treatment of the nasal septum in the form of submucous resection of the deviated bony and cartilaginous septum was first described by Ingals in 1892. It was subsequently modified by both Freer and Killian. ${ }^{5-7)}$ In the middle of the 20th century, many other studies focused on preserving cartilage and selectively raising submucoperichondrial flaps. Therefore, several septoplasty variations have been proposed. Endonasal, external, and endoscopic approaches are all widely accepted methods for septoplasty.

Despite advances in surgical techniques however, septoplasty is not always successful and prior studies have indi- 
cated that the outcomes of septoplasty are by no means satisfactory overall. Dinis and Haider ${ }^{8)}$ found that only $42 \%$ of patients responding to a satisfaction questionnaire reported a good to excellent result, with the majority reporting either a moderately successful result $(35 \%)$ or a poor result $(23 \%)$. These results can explain the increase in the need for revision septoplasty. In our current study, about $13.5 \%$ of patients underwent revision surgery more than once. This finding further demonstrates how difficult it is to achieve satisfactory treatment outcomes after septoplasty.

In the earlier study by Dinis and Haider ${ }^{8)}$ found a significant correlation between the presence of anterior septal deviation and the postoperative satisfaction of patients. In our current study, over $89 \%$ of patients showed caudal septal deviation, which is consistent with the findings of Dinis and Haider $^{8)}$ Also, in recent prospective study, Gillman, et al. ${ }^{9)}$ found that caudal septal deviation can be a critical cause of nasal obstruction after primary septoplasty due to narrowing of the external valve area and the nasal valve angle.

There are several techniques, such as suturing, swinging door, septal batten, ethmoid bone sandwich graft, tongue in groove, and extracorporeal septoplasty, that are used to manage caudal septal deviation. ${ }^{10)}$ This broad range of approaches demonstrates the difficulty of correcting caudal septal deviation. In our present study cohort, batten grafting with the cutting and suture technique or batten grafting alone was mainly performed. In some cases, we used the cutting and suture technique alone, a spreader graft, or an anchoring suture. These techniques might be effective in revision cases in which nasal obstruction has persisted due to remnant or recurrent caudal septal deviation. There were no cases of recurrence of deviation after revision surgery in our current patient series.

The use of batten grafting to support the caudal septum was first described by Dingman, and several studies have since reported on this procedure. ${ }^{10-16)}$ Batten grafting can be performed either via endonasal or external approaches. Harvested septal cartilage has typically been used as the batten graft material, although some studies recently reported on the usefulness of nasal septal bone for deviated caudal septum correction. ${ }^{17,18)}$ The senior author of this article introduced the technique of cutting and suturing the caudal L-strut via an endonasal approach for the management of caudal septal deviation. ${ }^{19)}$ If the stability of the sutured overlapping caudal septum is in doubt, he uses a batten graft on the concave side of deviated septum for further support. This graft can significantly enhance the effect of the cutting and suture technique. He found that batten grafting at the caudal septum and the cutting and suture technique showed an equivalent efficacy for improving nasal obstruction. ${ }^{20)}$ As for the material of batten graft, we used harvested septal cartilage in about $65 \%$ of our patients. The second most commonly used material was harvested nasal septal bone. In cases where the amount of septal cartilage available for grafting is limited, use of the septal bone as an internal splint may allow easier straightening of the bent caudal septum. Two previous studies have reported that autologous septal bone grafts are an excellent alternative to traditional cartilage grafts to support a deviated or a weak caudal septum. ${ }^{18,19)}$ Conchal cartilage was also used if there was insufficient septal cartilage or bone for batten graft.

In our current study cohort, postoperative infection developed in two cases and postoperative septal hematoma in three cases in spite of using postoperative splints. These adverse events were successfully controlled with oral antibiotics and/ or incision and drainage. Infection might be the result of the suture material, bilateral flap elevation, or transmucosal sutures. Among the 3 patients who complained of persistent nasal obstruction, one underwent radiofrequency turbinate volume reduction at both inferior turbinates. Two patients with minor synechia underwent synechiolysis at an outpatient clinic under local anesthesia. One patient with posterior small septal perforation did not have any symptoms and did not require further management. For 1 patient with a mucosal defect, we tried to induce natural healing of the mucosa by conservative dressing, but it did not heal successfully. Therefore, we performed a skin grafting using postauricular skin under local anesthesia.

The results of our current study show that the subjective satisfaction scores of the patients analyzed are not that high suggesting that revision septoplasty is a much more complicated procedure than primary septoplasty. However, it can be done effectively if a complete and correct diagnosis of the problems is made and the proper approaches and techniques are used. Inferior turbinate procedures showed no statistically significant effect on subjective satisfaction score. It might be due to the small numbers of patients who answered the telephone interview. Also turbinate surgery might have a low influence on nasal obstruction at revision surgery.

The nasal valve area is considered to have the lowest crosssectional area of the nose, and nasal valve collapse is one of the important causes of nasal obstruction. However, it is commonly missed when a surgeon tries to identify problems before the septoplasty. Becker, et al. ${ }^{3)}$ found that a lack of im- 
provement after primary septoplasty was often due to factors that affect the airway other than the septum, such as the nasal valve. Because Westerners have a thin skin and relatively narrow nasal valve angle, nasal valve collapse should be considered one of the important causes of nasal obstruction. However, it was not a considerable problem in our study, possibly due to the thick skin and wide internal nasal valve angle of Asians in comparison with Westerners. ${ }^{21)}$

Our present study had some limitations of note. The retrospective study design with no randomization of the study population is the main weakness. The validated satisfaction measurement such as the Nasal Obstruction Symptom Evaluation (NOSE) scale can be useful which is performed in other studies. ${ }^{9)}$ In addition, we did not use an objective evaluation such as acoustic rhinometry. We did not consider acoustic rhinometry to be a reliable tool for assessing caudal septal deviation because the nosepiece could have distorted the caudal septum. However, in spite of several limitations above, this study is meaningful to suggest the algorithm of revision septoplasty and analyze several useful techniques for managing caudal septal deviation. The results could be valuable in the future in assisting surgeons to make proper treatment plans for revision septoplasty.

In conclusion, revision septoplasty is a very challenging procedure, even for skilled surgeons. We find in our current study that a significant number of patients who undergo revision septoplasty have a remnant or recurrent caudal septal deviation that was not properly corrected in a previous surgery. We recommend the batten graft and cutting and suture technique for the correction of caudal septal deviation in revision septoplasty.

\section{REFERENCES}

1) Gray LP. Deviated nasal septum. Incidence and etiology. Ann Otol Rhinol Laryngol Suppl 1978;87(3 Pt 3 Suppl 50):3-20.

2) Manoukian PD, Wyatt JR, Leopold DA, Bass EB. Recent trends in utilization of procedures in otolaryngology-head and neck surgery. Laryngoscope 1997;107(4):472-7.
3) Becker SS, Dobratz EJ, Stowell N, Barker D, Park SS. Revision septoplasty: review of sources of persistent nasal obstruction. Am J Rhinol 2008;22(4):440-4.

4) Bothra R, Mathur NN. Comparative evaluation of conventional versus endoscopic septoplasty for limited septal deviation and spur. J Laryngol Otol 2009;123(7):737-41.

5) Ingals EF. Deflection of the septum narium. New York: GP Putnam's Sons; 1882.

6) Freer OT. The correction of deflections of the nasal septum with a minimum of traumatization. JAMA 1902;38(10):636-42.

7) Killian G. Die submucose Fensterreaktion der Nasen scheidewand. Arch Laryngole Rhinol 1904;16(3):S203f.

8) Dinis PB, Haider H. Septoplasty: Long-term evaluation of results. Am J Otolaryngol 2002;23(2):85-90.

9) Gillman GS, Egloff AM, Rivera-Serrano CM. Revision septoplasty: a prospective disease-specific outcome study. Laryngoscope 2014; 124(6):1290-5.

10) Haack J, Papel ID. Caudal septal deviation. Otolaryngol Clin North Am 2009;42(3):427-36

11) Dingman RO. Correction of nasal deformities due to defects of the septum. Plast Reconstr Surg (1946) 1956;18(4):291-304.

12) Dupont C, Cloutier GE, Prevost Y. Autogenous vomer bone graft for permanent correction of the cartilaginous septal deviations. Plast Reconstr Surg 1966;38(3):243-7.

13) Goode RL. Nasal septal surgery. In: Krause CJ, Mangat DS, Pastoreck N, editors. Aesthetic Facial Srugery. Philadelphia, PA: J.B. Lippincott Co;1991. p.133-60.

14) Jang YJ. Correction of the deviated nose. In: Jang YJ, Park CH, editors. Practical Septorhinoplasty: An Asian Perspective. Seoul: Koonja Publishing Inc;2007. p.239-73.

15) Metzinger SE, Boyce RG, Rigby PL, Joseph JJ, Anderson JR. Ethmoid bone sandwich grafting for caudal septal defects. Arch Otolaryngol Head Neck Surg 1994;120(10):1121-5.

16) Dyer WK, Kang J. Correction of severe caudal deflections with a cartilage "plating" rigid fixation graft. Arch Otolaryngol Head Neck Surg 2000;126(8):973-8.

17) Jang YJ, Kim JM, Yeo NK, Yoo JH. Use of nasal septal bone to straighten deviated septal cartilage in correction of deviated nose. Ann Otol Rhinol Laryngol 2009;118(7):488-94.

18) Dini GM, Iurk LK, Ferreira MC, Ferreira LM. Grafts for straightening deviated noses. Plast Reconstr Surg 2011;128(5):529e-37e.

19) Jang YJ, Yeo NK, Wang JH. Cutting and suture technique of the caudal septal cartilage for the management of caudal septal deviation. Arch Otolaryngol Head Neck Surg 2009;135(12):1256-60.

20) Kim JH, Kim DY, Jang YJ. Outcomes after endonasal septoplasty using caudal septal batten grafting. Am J Rhinol Allergy 2011;25(4): e166-70.

21) Suh MW, Jin HR, Kim JH. Computed tomography versus nasal endoscopy for the measurement of the internal nasal valve angle in Asians. Acta Otolaryngol 2008;128(6):675-9

22) Jang YJ. Rhinoseptoplasty. Seoul: Koonja;2013. p.77-81. 